\title{
DIETARY TREATMENT OF HYPERTENSION. II. SODIUM DE- PLETION AS RELATED TO THE THERAPEUTIC EFFECT ${ }^{1}$
}

\author{
By VINCENT P. DOLE, LEWIS K. DAHL, GEORGE C. COTZIAS, DOMINIC D. \\ DZIEWIATKOWSKI, AND CECILIA HARRIS
}

(From the Hospital of The Rockefeller Institute for Medical Research, New York, N. Y.)

(Submitted for publication October 31, 1950; accepted, March 26, 1951)

\begin{abstract}
Abnormal accumulations of sodium have been demonstrated by direct analysis of the tissues of dogs (1) and rats (2) that had been made hypertensive by renal ischemia. These observations are of special interest because of the reductions of blood pressure in hypertensive patients that may be induced by means of extreme restriction of the dietary sodium. Taken together, these facts suggest that the benefit experienced by the patients might be due to the removal of excess sodium.
\end{abstract}

On the other hand, it must be recognized that hypertension is not a necessary, or even a usual, consequence of sodium retention. Accumulations of extracellular fluid in association with normal levels of blood pressure are of frequent occurrence in a variety of diseases, including renal disorders. Therefore, if the retention of sodium is to be regarded as contributory, rather than as merely incidental, to the development of hypertension, it must be linked to some other metabolic disturbance in this particular disease.

In the present study five hypertensive patients were subjected to large changes in their rations

1 The radiosodium used in this investigation was supplied by Oak Ridge on allocation from the Isotopes Division, United States Atomic Energy Commission. of dietary sodium. Resultant changes in the sodium content of their bodies were measured by isotope dilution. These observations have been correlated with the changes in their clinical status and with inferred changes in the degree of cellular hydration. It is suggested that the latter may be the important factor that is linked to the depletion of sodium.

\section{PROCEDURE}

Five patients with benign and uncomplicated hypertension were chosen for a study. Apart from Grade I changes in their ocular fundi and slight enlargements of the heart shadow in their chest films, the results of physical and laboratory examinations were negative. In particular all patients had normal urea clearances and absence from the urine of significant quantities of protein, casts and cells. Further clinical data are summarized in Table I; similar data also are given for the three normal subjects who served as controls in the measurement of exchangeable sodium.

During the five to seven months of this study the patients remained entirely on the metabolic ward, except for a vacation of three days during the Christmas season. Confinement to a hospital ward necessarily limited the physical activity of each patient; at no time, however, were the patients restricted to bed.

A central feature in the design of the investigation was the provision of an extended time during which the sodium intake was maintained at a high normal value (180

TABLE I

Clinical data

\begin{tabular}{|c|c|c|c|c|c|c|c|}
\hline Patient & $\begin{array}{l}\text { R. I. H. } \\
\text { No. }\end{array}$ & Age & Sex & $\begin{array}{l}\text { Family history } \\
\text { of hypertension }\end{array}$ & $\begin{array}{l}\text { Known duration } \\
\text { of hypertension }\end{array}$ & $\begin{array}{l}\text { Disease other } \\
\text { than } \\
\text { hypertension }\end{array}$ & $\frac{\begin{array}{c}\text { Ratio } \\
\text { initial wt. }\end{array}}{\text { ideal wt.* }}$ \\
\hline $\begin{array}{l}\text { A } \\
\text { B } \\
\text { C } \\
\text { D } \\
\text { E }\end{array}$ & $\begin{array}{l}12,450 \\
12,447 \\
12,451 \\
12,453 \\
12,465\end{array}$ & $\begin{array}{c}\text { years } \\
26 \\
44 \\
27 \\
39 \\
41\end{array}$ & $\begin{array}{l}\text { female } \\
\text { female } \\
\text { male } \\
\text { female } \\
\text { male }\end{array}$ & $\begin{array}{c}++t \\
0 \\
+ \\
0 \\
0\end{array}$ & $\begin{array}{c}\text { years } \\
4 \\
7 \\
5 \\
19 \\
10\end{array}$ & $\begin{array}{c}0 \\
0 \\
\text { migraine } \\
0 \\
0\end{array}$ & $\begin{array}{l}1.12 \\
1.07 \\
1.12 \\
1.06 \\
1.12\end{array}$ \\
\hline $\begin{array}{l}\mathrm{F} \\
\mathrm{H}\end{array}$ & $\begin{array}{l}\text { normal control } \\
\text { normal control } \\
\text { normal control }\end{array}$ & $\begin{array}{l}35 \\
37 \\
28\end{array}$ & $\begin{array}{l}\text { male } \\
\text { male } \\
\text { male }\end{array}$ & $\begin{array}{l}0 \\
0 \\
+\end{array}$ & $\begin{array}{l}0 \\
0 \\
0\end{array}$ & $\begin{array}{l}0 \\
0 \\
0\end{array}$ & $\begin{array}{l}1.01 \\
1.06 \\
0.85\end{array}$ \\
\hline
\end{tabular}

* "Ideal weight" for each patient was calculated from normal values which had been derived from life insurance statistics (7). 
meq./day) by the addition of salt tablets to a diet otherwise low in sodium (less than 7 meq./day). During this preliminary time, changes in the daily intakes of water and of protein were imposed in order to demonstrate any clinical effects of these factors in the absence of sodium restriction. After from two to four months had elapsed, the intake of sodium was reduced to the $7 \mathrm{meq}$./day level by omission of the supplementary tablets. Ten weeks later the sodium intake was returned to the higher level by resumption of the supplement in order to test the reversibility of the clinical and metabolic changes which had followed the restriction of this element.

The detailed timing of these manipulations may be seen in the figures. The total study was divided into six periods, which are separated in all the figures by vertical lines. These periods were differentiated by changes in the water or the sodium intake; one of these two factors remained constant throughout any consecutive pair of periods while the other was changed. An upward direction of the arrow in relation to the symbols in the figures indicates that this factor was administered in high dosage during the period; a downward direction indicates the converse. For sodium the high dosage level was 180 meq./day and the low dosage was the residual amount in the diet alone, namely a value less than 7 meq./ day. During the periods of high water intake, 4,500 cc./ day of fluid were administered in addition to the preformed and metabolic water of the diet; as a result the urinary volumes were maintained at high average values (Table II). Water restriction in the low dosage periods was carried to the point of slight thirst; an intake of 800 to $1,000 \mathrm{cc}$./day of supplementary fluid, which maintained the urinary volumes in the range 600 to $900 \mathrm{cc}$./day, appeared to be the minimum tolerable fluid supplement when sodium was concurrently administered in high dosage. In the figures a symbol for water in Period $I$ is absent because the patients were allowed uncontrolled access to water; during this time their urine volumes ranged between 800 and $1,800 \mathrm{cc}$./day.

The changes in level of protein intake are indicated in Figure 3. It may be seen that the daily consumption was 30-40 grams until the middle of Period III, when the amount was approximately doubled. Prior to this time the patients had felt dissatisfied with the diet despite the fact that it was as diversified as was compatible with the requirement of sodium restriction, and was unlimited in quantity except with respect to the foods of moderate sodium content. Since the usual high protein foods fell into the latter category, the protein intake was curtailed until Period III, when a special low sodium, high protein food ${ }^{2}$ was made available for the patients to take in amounts regulated by their appetites. During Period IV they continued to take the increased amount of protein; with the restriction of water in Periods V and VI the

2 "Low sodium food," Wyeth : protein, 50 per cent ; carbohydrate, 19.5 per cent; fat, 25 per cent; total ash, 3.5 per cent; sodium, 0.02 per cent. A generous supply of this product was donated by Wyeth, Inc. amount of this supplement that could be conveniently given was limited by the lack of fluid for its suspension.

One exception to the plan of deferred sodium restriction should be noted: through oversight, the supplementary salt tablets were not ordered for Patient C. When the omission was discovered he had already shown a reduction in blood pressure below the value on admission and the earlier values that had been observed in the out-patient clinic. Therefore, it was decided to continue the study of his response without the supplement until the final period.

\section{METHODS}

Daily measurements of blood pressure and of body weight were made each morning except Sundays under standardized conditions. The blood pressure was determined by the same physician for each patient; at least 20 minutes of bed rest preceded the reading. Body weight was measured after urination and before breakfast on a calibrated scale that was accurate to 100 grams; the patients were nude except for a covering sheet of known weight.

At biweekly intervals a standard 2 meter chest film was obtained for measurement of heart size. At monthly intervals the basal metabolic rates were measured, and electrocardiographic tracings taken.

A total collection of urine was made, and divided into 24 hour pools; analyses of sodium, potassium and chloride concentrations were made upon each, using methods previously discussed (3). During two intervals of five days each, at the ends of Periods IV and VI, collections of stools were made; the total output from each interval was pooled and analyzed for sodium and potassium (3).

The determination of exchangeable sodium was based on the dilution of a measured dose of radiosodium. An infusion fluid containing $0.8-1.0 \mu \mathrm{c}$ of $\mathrm{Na}^{24} \mathrm{Cl} / \mathrm{cc}$. of 5 per cent dextrose in water was injected intravenously from a calibrated $100 \mathrm{cc}$. burette at a dose of just $1 \mathrm{cc}$./ kg. ${ }^{3}$ Samples of blood were taken at hourly intervals for seven hours; in some tests additional samples were taken after 24 and 48 hours.

With a Tracerlab $\beta$ - $\gamma$ dip-counter (TGC-5) and autoscaler, measurements of the radioactivity of the samples were made after dilutions that were sufficient to bring the counting rates within the range of linear response of the tube. An equilibrium value (a) of the specific activity of the serum (ratio of radioactivity in arbitrary units to the sodium concentration) as attained in the five to seven hour interval was estimated graphically. The quantity (q) of sodium with which the injected dose (d) of tracer had been mixed was calculated from the relation $q=d / a$. This quantity is about 10 per cent less than that which would be calculated from the 24 hour equilibration of specific activitud therefore does not include the ${ }^{3}$ alculation

${ }^{3}$ Calculation based on the data given by Marinelli and associates (4) indicated that the patients were exposed by this test to less than 0.1 equivalent roentgen of radiation during the first 24 hours and to negligible amounts thereafter. 
V. P. DOLE, L. K. DAEL, G. C. COTZIAS, D. D. DZIEWIATKOWSKI, AND C. HARRIS

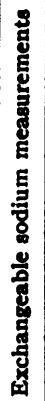

\begin{tabular}{|c|c|c|c|c|c|c|c|c|c|c|c|c|c|c|}
\hline & $\underset{\sim}{\mathrm{g}}$ & : & :్ & 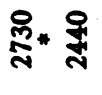 & 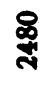 & " . & $\approx$ & 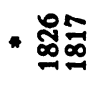 & $\stackrel{\circ}{\infty}$ & 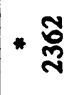 & ్ㅠㅀ & 웡유 & สิ & . \\
\hline$\&$ & $\dot{y}$ & 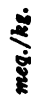 & बें & 品 & ले & * & $\vec{\infty}$ & * जेंत्र & 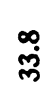 & " & लें & దొ & m్ల & \\
\hline
\end{tabular}

\begin{tabular}{|c|c|c|c|c|c|c|c|c|c|c|c|c|c|c|c|c|c|c|c|}
\hline 莺 & 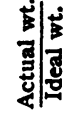 & $\dddot{7}$ & $\stackrel{\Delta}{*}$ & $\stackrel{\text { ֻ }}{-}$ & 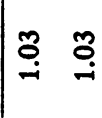 & ס̊ & $\stackrel{\text { og }}{-1}$ & نَ & - & $\stackrel{-}{0}$ & वू. & @̊ & $\stackrel{\infty}{\circ}$ & $\cong$ & $\stackrel{5}{-}$ & $\stackrel{\text { ¿ }}{\circ}$ & 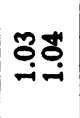 & $\stackrel{\%}{\mathscr{0}}$ & : \\
\hline & 胥 & 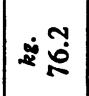 & ò & $\stackrel{m}{i}$ & 옹 & هั. & ก̃ & 8̊ & i & 号 & مै० & $\begin{array}{l}\infty \\
\text { ڤึ }\end{array}$ & $\overrightarrow{\text { in }}$ & व: & ชุ่ & ㅇ. & हैं & $\hat{B}$ & \\
\hline
\end{tabular}

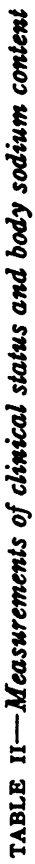

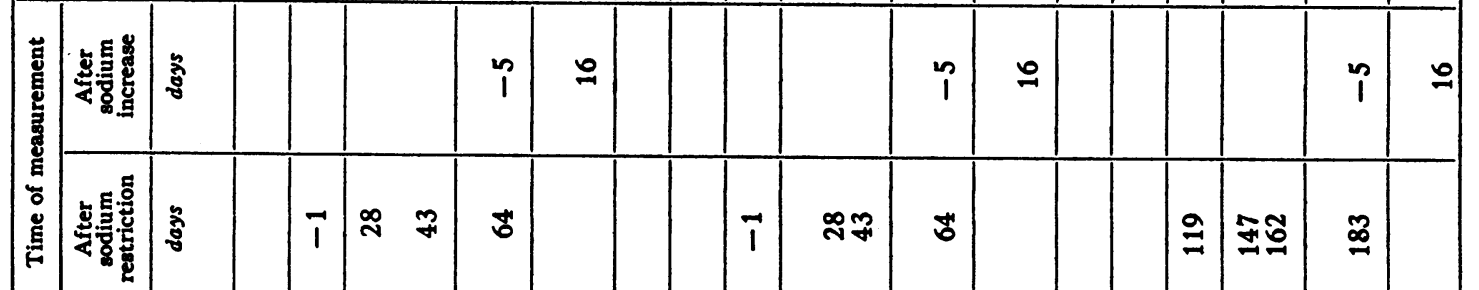

\begin{tabular}{|c|c|c|c|c|c|c|c|c|c|c|c|c|c|c|c|c|c|c|c|}
\hline &  & 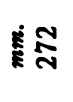 & $\overline{\text { ก }}$ & $\stackrel{N}{N}$ & $\stackrel{\infty}{\circ}$ & ลั & ลิ & ఫ్రి & : & జ్ & $\stackrel{\infty}{\text { స్ }}$ & ปั & $\stackrel{\tilde{N}}{*}$ & సે & สั & 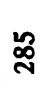 & ঐి & ๙ั & ๙ \\
\hline & 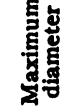 & $\dot{E}$ & 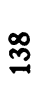 & ஓ్ & * $\cong$ & $\stackrel{\infty}{=}$ & * $\stackrel{\infty}{\stackrel{m}{\sim}}$ & ฏे & gे & 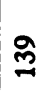 & స్త్ & $\stackrel{m}{-2}$ & 웜 & I & $\mathcal{Z}$ & ले & $\stackrel{0}{ \pm}$ & 早 & \\
\hline
\end{tabular}

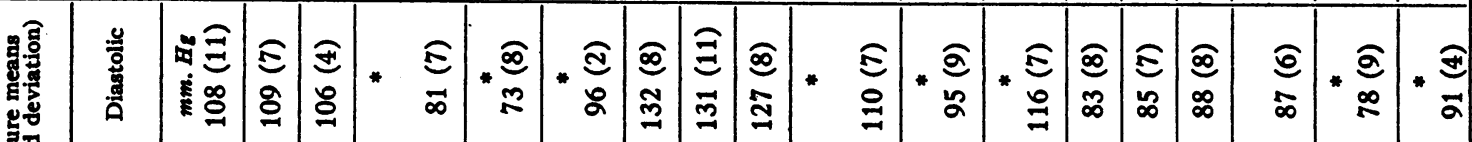

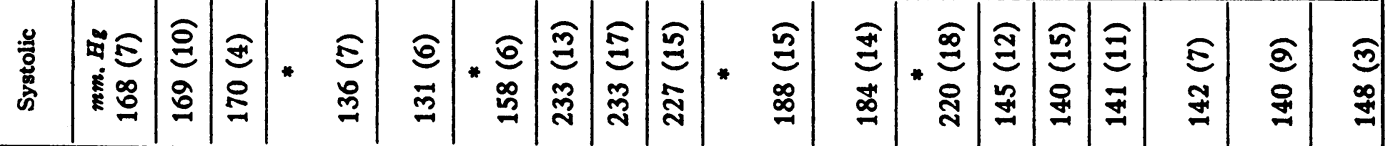

\begin{tabular}{|l|l|l|l|l|l|l|l|l|l|l|l|l|l|l|l|l|l|}
\hline \\
\hline
\end{tabular}

\begin{tabular}{|c|c|c|c|c|c|c|c|c|c|c|c|c|c|c|c|c|c|}
\hline 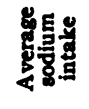 & 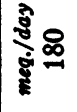 & $\stackrel{\circ}{\stackrel{0}{-1}}$ & $\stackrel{\mathscr{\Xi}}{\sim}$ & - & $\sim$ & 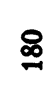 & 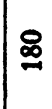 & 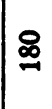 & 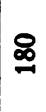 & $\sim$ & - & 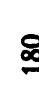 & $\sim$ & - & - & - & - \\
\hline
\end{tabular}

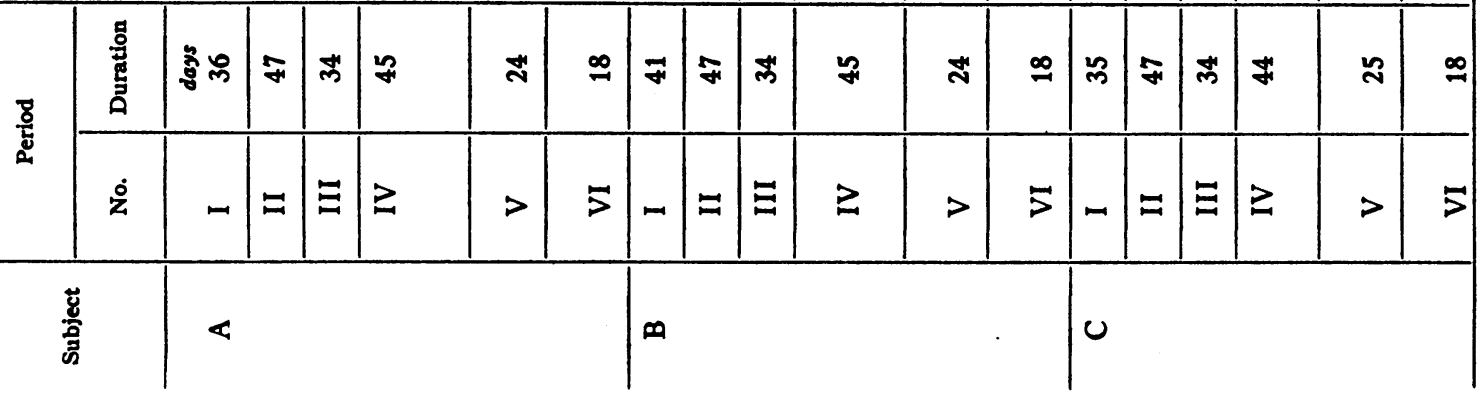


DIETARY TREATMENT OF HYPERTENSION. II

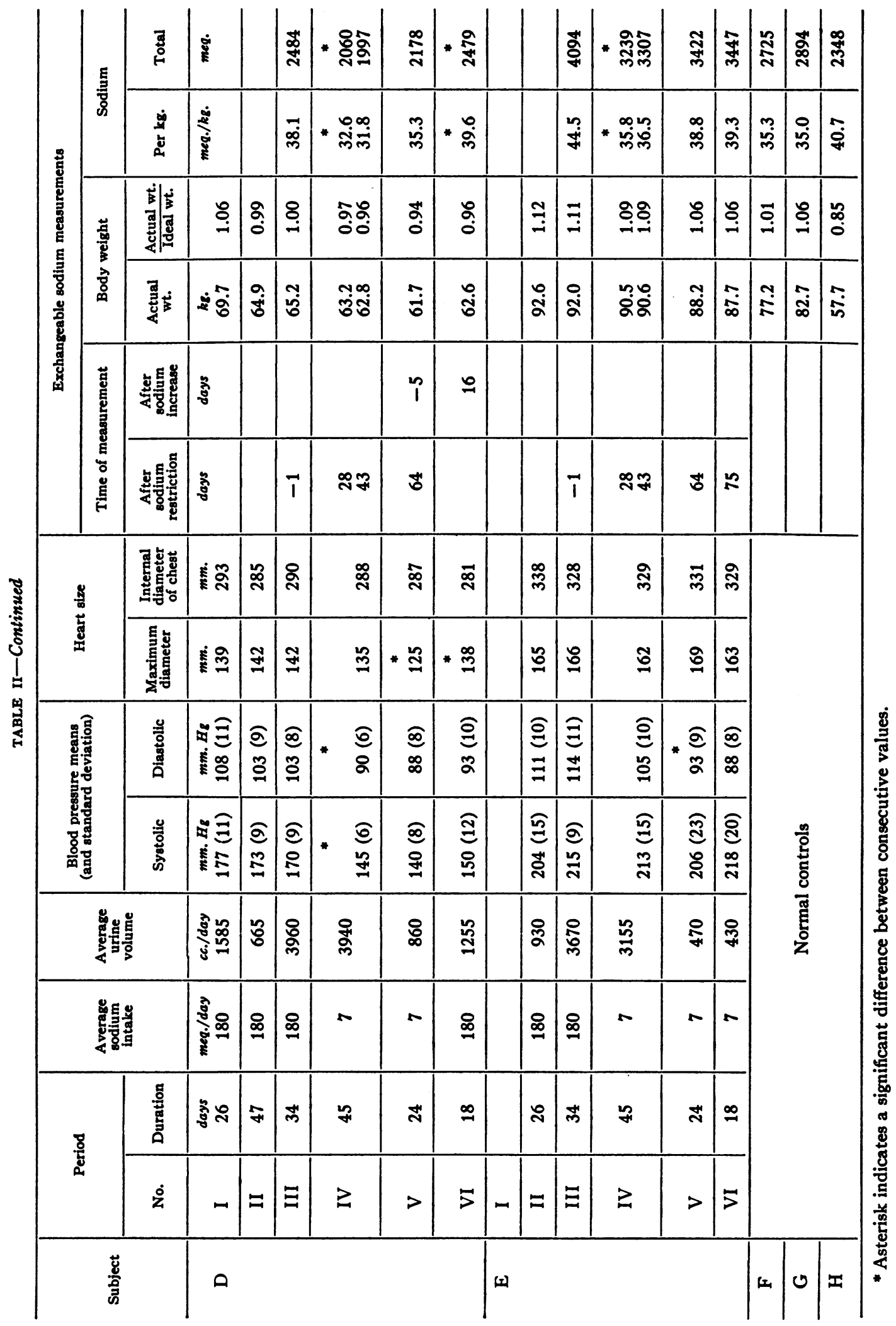


most slowly equilibrating sodium in the body. It is to be expected, however, that equilibration would have been complete in the soft tissues which have been shown (1, 2) to accumulate sodium in the animals with hypertension.

\section{Criteria of Significance}

Average values of blood pressure were calculated from the consecutive readings obtained during the last two weeks of each period except Period VI for which only the last week was taken. Fisher's "t test" (5) was used to calculate the probability that the differences between successive averages might occur by chance alone. Changes were considered significant when this probability was less than 0.01 ; these changes are indicated by an asterisk in Table II.

Heart diameter on a given chest film could be measured reproducibly within $2 \mathrm{~mm}$. In order to exclude the effects of differences in projection and heart cycle it was taken as necessary that changes must exceed $10 \mathrm{~mm}$. to be significant. These are indicated in Table II.

The exchangeable sodium is calculated from four primary measurements: the counting rates of solution injected and of the serum at equilibrium, the volume of fluid injected and the sodium concentration of the serum sample. Since the fluid was delivered into the subject from a calibrated burette which was accurate to less than $0.1 \mathrm{cc}$., the error in this factor may be neglected. The average counting rates of the diluted infusion fluid, diluted serum and the background were 5,000, 400, and 44 cpm., respectively, and were counted for $20,480,2,048$, and 4,096 total counts. From these values it may be estimated that the coefficients of variation (ratio of standard deviation to mean value) were 0.007 and 0.022 , respectively, for the infusion fluid and the serum samples (6). For the variation in the determination of total sodium concentration the coefficient 0.020 was assumed. These factors contribute to the uncertainty of estimation of their product according to the formula $E=\left(F^{2}+S^{2}+C^{2}\right)^{1 / 2}$ where the symbols indicate the coefficients of variation of the exchangeable sodium, the infusion fluid counting rate, the serum counting rate, and the serum sodium concentration, respectively. Substitution of the values above give $E=0.031$. Since the final value for body sodium was based on at least three independent serum samples the coefficient for the final result is reduced by the factor $(1 / \sqrt{3})$ and thus was approximately 0.02 . In the case of an adult of average weight this value corresponds to a standard deviation of less than 60 meq. The changes discussed in this paper were of considerably greater magnitude; in Table II, under the heading of "Exchangeable sodium," the asterisks signify a change of five standard deviations or more.

\section{OBSERVATIONS}

The blood pressures of all patients remained elevated during the periods in which the intake of sodium was maintained at 180 meq./day (Figure 1). During the two to four months which were spanned by these three periods, large variations of water intake were imposed and considerable losses of weight occurred; there were no significant changes in the average values of blood pressure or in the heart sizes (Table II).

When the sodium was reduced to the dietary level of about 7 meq./day by omission of the tablets, a statistically significant reduction of blood pressure was observed in each patient. Of the five patients three became normotensive (or nearly so), while the other two remained in the hypertensive range. The latter patients had the most marked elevations of blood pressure during the control periods and, therefore, would have had to experience greater reductions in order to approach the normal range.

Three of the four patients who were given salt tablets in the final period showed increases in their average blood pressures. Since the trend of the daily blood pressure values was upward in Period VI (Figure 3 ), it is probable that even higher averages would have been obtained in a more extended period. With the return of hypertension there were increases of the heart size which abolished earlier reductions (Table II).

Weight losses were observed in all patients (Figure 2). The graphical form of the weight curves was similar to that previously reported for a group of patients who received the rice-fruit diet (3); with both diets the weight losses proceeded at a rate which was rapid at first but which decreased with time. The rates of adaptation were so slow, however, that several additional months probably would have been required for attainment of definite weight equilibrium.

Since the caloric intakes of the patients remained under their control, it is evident that some factor in the regimen must have reduced their appetites. This factor certainly was not restriction of sodium since four of the five patients of the present study received 10 grams $\mathrm{NaCl} /$ day during the initial phase of rapid loss, and the remaining patient $(\mathrm{C})$, who received no salt supplement, experienced a weight loss which was indistinguishable from the others. Moreover, the weight changes were not related to adaptation of the basal metabolic rates; these were measured at monthly intervals and were found to remain within normal limits $( \pm 10$ per cent) in all patients.

The explanation which seems most probable is that the limitation of protein intake caused the 


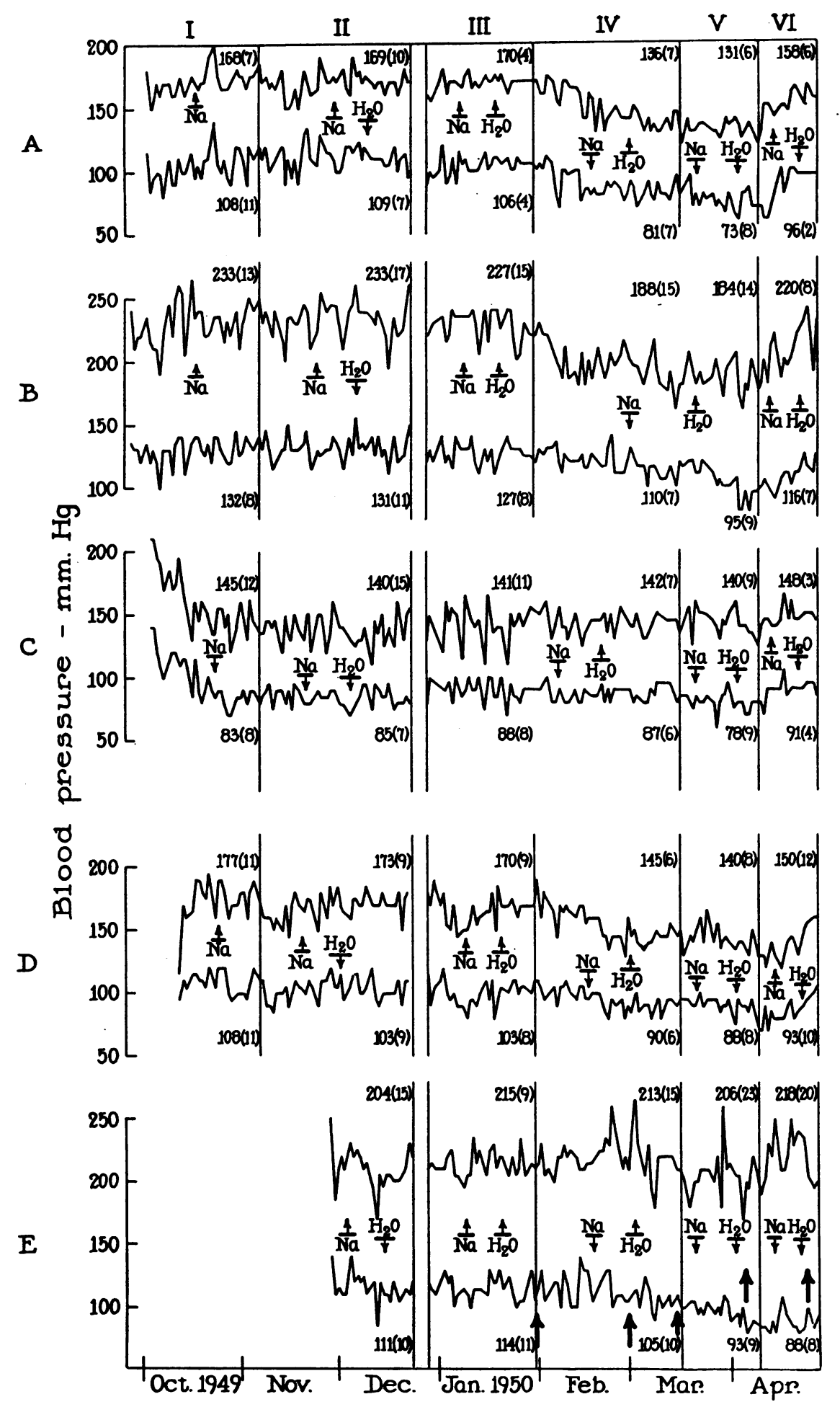

Fig. 1. Morning Values of the Systolic and Diastolic Blood Pressures

The numbers near the end of each period are the averages and the standard deviations for the last two weeks of each period, except the last for which a one week average was taken. Sodium intake was 180 meq./day during periods with the arrow up, and 7 meq./day during those with arrow down. High and low water intakes, indicated similarly, were $4,500 \mathrm{cc}$./day and 800 to $1,000 \mathrm{cc}$./day, respectively. 
weight losses. The basic diet was deficient in protein, as compared to the standard which was established by the patients themselves when given free choice in the matter, since each patient nearly doubled his protein intake when the protein supplement was made available for unlimited consumption (Figure 3, Periods III and IV). With the increased intakes of protein there were associated

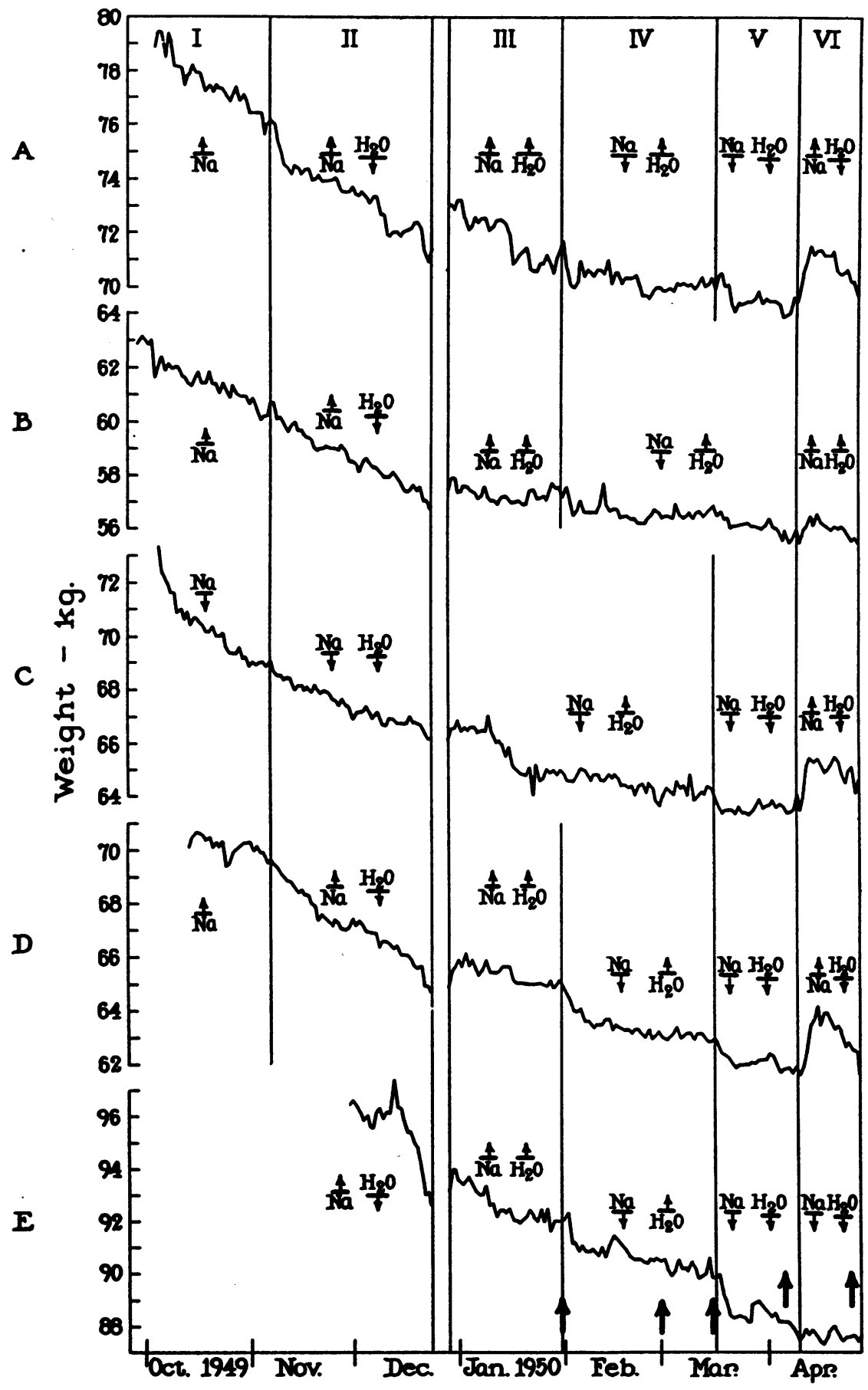

Fig. 2. Morning Weights

Symbols are defined in the legend of Figure 1. 
increases of non-protein calories, amounting to 100 to 300 calories per day.

A more direct demonstration of the relation between protein intake and change in body weight under the conditions of this study has been obtained in subsequent work. Three other patients, who were given the same diet under the same circumstances except that their protein intakes were maintained from the onset at 70-90 grams/day by a prescribed administration of the supplement, not only failed to lose weight but actually gained 1 to $4 \mathrm{~kg}$. during a three month period of observation.

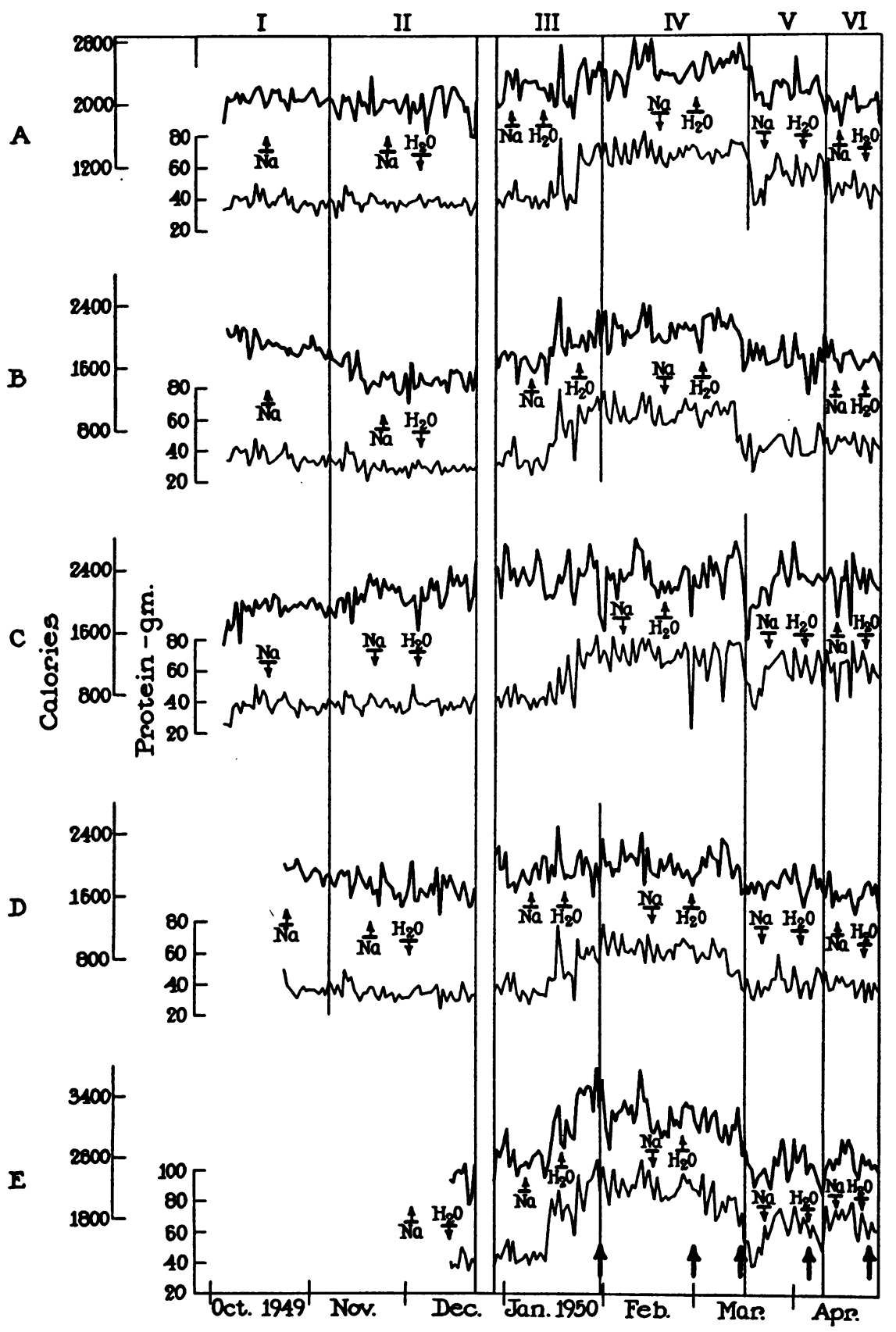

Fig. 3. Calculated Daily Consumptions of Total Calories and of Protrin Symbols are defined in the legend of Figure 1. 
The changes in exchangeable sodium are shown in Table II. The hypertensive patients, before omission of the salt supplement, did not differ from the three normal subjects with respect to the quantity of exchangeable sodium per unit body weight. These data do not exclude the possibility that a small difference between the average values of hypertensives and normals might be demonstrable in a larger series, but they indicate that the hypertensive subjects are not distinguished from the normals by a consistent or gross discrepancy.

The first measurements of exchangeable sodium were made at the end of Period III, two days before reduction of intake from 180 to 7 meq./day; the second were made one month later. In three of the four patients a reduction of 14-20 per cent was found. The explanation for the failure of $\mathrm{Pa}$ tient $\mathrm{A}$ to conform is not apparent; however, at the time of the third measurement two weeks later she was found to have a comparable reduction, while the other patients were unchanged. The fourth measurements were made three weeks later (a total of nine weeks from reduction of the sodium intake) and showed no further change in any of the patients.

The final measurements were made 16 days after the sodium intake had been returned to 180 meq./ day. In the three patients $(A, B, D)$ for whom the comparison could be made it was found that the exchangeable sodium had been returned to the control level.

The concentration of sodium in the serum was measured with each determination of exchangeable sodium. In contrast to the large changes which occurred in the latter, the concentration was not significantly affected by the variations of sodium intake.

The urinary excretions of sodium are shown graphically in Figure 4. Following reduction of their sodium intakes, the patients reduced their urinary excretions quite slowly: at least a week was required for reduction to the level of dietary intake. By the third week the urinary loss had fallen to $1 \mathrm{meq}$./day or lower, the output at this extremely low level being somewhat accelerated by a large urine volume and reduced with restriction of fluids.

After increase of the sodium intake in Period VI, the urinary excretions rose. Again there was a lag in the renal response to the changed situation.
When the fecal excretions of sodium were measured during the last five days of Period IV and of Period VI, it was found that the daily losses by this avenue averaged less than 1.5 and 2.2 meq./ day, respectively. Losses of this magnitude, although important with respect to a long-term balance under severe restriction of intake (3), evidently are negligible by comparison with the acute imbalances between intake and urinary excretion that were observed to follow a radical change in the level of intake. Therefore, since no gross sweating occurred during these observations, it is probable that the changes in the exchangeable sodium were due mostly to the lags in adjustment of the urinary excretion. Given time, the patients were able to resist further depletion, as shown by the constant values of the exchangeable sodium in the second, third, and fourth measurements; conversely, in the periods of high sodium intake they maintained a constant urinary excretion despite wide variations in their urine volumes.

It will be observed that the decreases in exchangeable sodium (Table II) were greater than the urinary excretions of the element during the first five days after reduction of intake (Table III). The probable reason for this is that the isotope equilibrations were attained in the afternoon, when the sodium ration of the day had been absorbed but not yet excreted (unpublished observations). The data for the excretions during the 14 hours that followed the last dose of $\mathrm{NaCl}$ were omitted from the calculations of Table III in order to present the ratios of sodium to chloride excretions on the subsequent days when no salt was administered.

The urinary excretions of chloride tended to parallel those of sodium. In particular it was noted that the net urinary losses of the two ele-

TABLE III

Comparison of the net urinary losses of sodium and chloride during the five days following omission of salt tablets

\begin{tabular}{c|c|c|c}
\hline \hline \multirow{2}{*}{ Patient } & \multicolumn{2}{|c|}{ Urinary output less dietary intake } & \\
\cline { 2 - 3 } & $\begin{array}{r}\mathrm{Na} \\
\text { meq./5 days }\end{array}$ & $\begin{array}{r}\mathrm{Cl} \\
\text { meq./5 days }\end{array}$ & $\mathrm{Na} / \mathrm{Cl}$ \\
\cline { 2 - 3 } $\mathrm{A}$ & 131 & 82 & 1.60 \\
$\mathrm{~B}$ & 144 & 119 & 1.21 \\
$\mathrm{D}$ & 146 & 132 & 1.11 \\
$\mathrm{E}$ & 166 & 115 & 1.44 \\
\hline
\end{tabular}




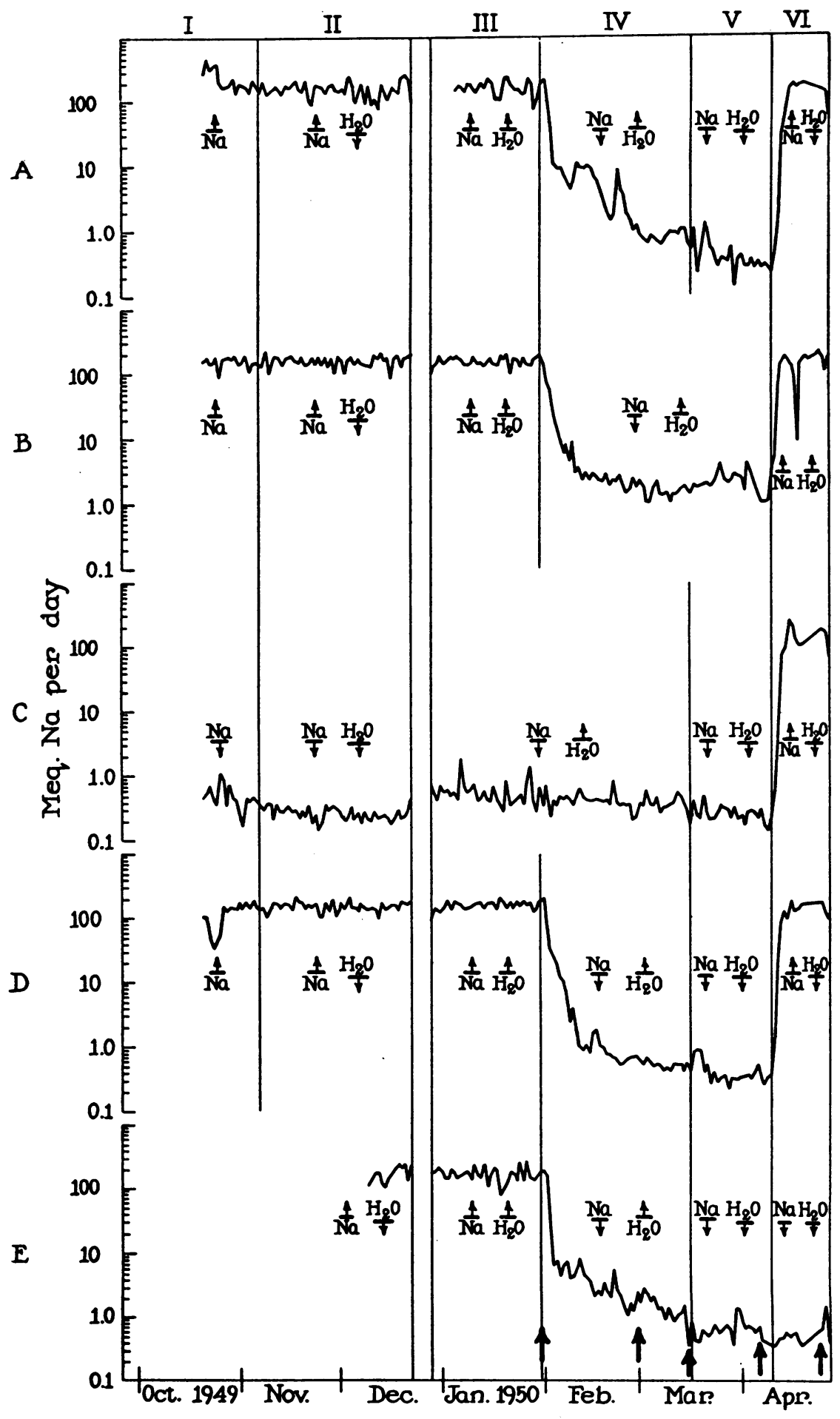

Fig. 4. URINe Sodium Excretions

Note that the ordinate scales are logarithmic. Symbols are defined in the legend of Figure 1. 
ments during the five days following reduction of intake occurred in ratios that approximated their ratios in extracellular fluid (Table III).

The urinary excretions of potassium tended to be greater during the early periods of rapid weight loss than subsequently. There was no clear relation of the urinary or fecal excretion of potassium to the changes in sodium intake.

\section{INTERPRETATION}

The proportional relation between the sodium and the chloride excretions on the days that followed reduction in intake (Table III) suggests that the sodium, which was lost from the body early in Period IV, was derived from a source with the composition of extracellular fluid. A similar inference with respect to reaccumulation may be drawn from the immediate weight changes that follow readministration of salt. It was observed in an earlier study (3), and confirmed in the present one, that the patients for a time gain weight at a rate which is just sufficient to account for the formation of extracellular fluid from the newlyavailable sodium.

It will be assumed, therefore, that the component of the body which gained and lost sodium as a result of the dietary changes was the extracellular fluid. If 20 per cent of the sodium of the extracellular fluid were lost, it would cause a profound drop in the concentration of sodium in the serum (e.g., to 115 meq./L or lower), unless the loss of sodium were compensated by a parallel loss of water. Therefore, since there were no significant changes in the concentration of sodium in the serum, it follows that water, as well as sodium, must have left the extracellular fluid at the time of the sodium loss, and conversely, that the extracellular volume must have expanded during reaccumulation.

It now becomes of interest to inquire into the fate of this extracellular water. If it had been excreted from the body, there would have been a weight loss of about $1 \mathrm{~kg}$. for every 140 meq. of sodium which were lost, providing that an immediate large increase in the solid matter of the body had not occurred. The latter possibility seems quite unlikely, partly because the antecedent weight curves show that body tissue was being lost rather than gained at the time of the sodium depletion, and partly because this hypothesis leads to the unlikely supposition that this solid matter was abruptly expelled following the subsequent reaccumulation of sodium. Since the weight losses of all patients fell significantly short of equivalence with their losses of exchangeable sodium (Table II), the simplest hypothesis is that part or all of the water which left the extracellular space did not leave the body. Under this interpretation the average cellular hydration was increased by about 5 per cent as a result of the sodium depletion.

This hypothesis also simplifies the explanation of the biphasic nature of the weight change (Figure 2) following readministration of sodium. The initial effect, as mentioned above, probably is an expansion of the extracellular fluid. The secondary effect is a loss of the newly-gained weight but, as shown by the elevated final value of exchangeable sodium, not of the sodium which was accumulated. Therefore it appears that the water which entered the cells during the previous adaptation to a low sodium intake was removed from them and excreted during the secondary phase of readjustment to a high intake of sodium.

The general interpretation which may be given to these changes is that there is a reciprocal relation between the volume of the extracellular fluid and the volume of part or all of the cellular fluids. A radical reduction in the level of dietary sodium shifts the balance slightly in the direction of cellular hydration and a return to a high intake level reverses the shift.

\section{CLINICAL-METABOLIC CORRELATION}

The persistent hypertension of all patients during the periods of high sodium intake was an impressive control for the reductions in blood pressure that occurred after omission of the salt tablets. Whether or not the antecedent two to four months of hospitalization, with the weight losses and the changes in protein metabolism, may have contributed to the ultimate therapeutic response cannot be said at present, but it is clear that these factors were not sufficient to reduce the blood pressure in the absence of sodium restriction.

The most obvious metabolic consequence of the reduction in sodium intake was the reduction in exchangeable sodium. However, this fact alone may not be a sufficient explanation of the clinical effect since there was no consistent correlation between the clinical status of the subjects and the quantity of exchangeable sodium per unit body 
weight. Moreover, the reductions in blood pressure and in exchangeable sodium were separated in time; the latter was mostly completed before the former became manifest.

Evidence has been brought forward to support the conclusion that the reduction of sodium intake caused an increase of intracellular water in addition to the contraction of extracellular volume. An indication that the change in intracellular water might be more closely related to the change in blood pressure than the change in extracellular volume is given by the delay in rise of blood pressure when salt was readministered; in this process it appears that the immediate effect is the expansion of extracellular volume and the delayed effect, which coincides with the blood pressure rise, is the expulsion of cellular water.

It is obvious that this hypothesis needs to be tested by direct measurements. Such test, however, must await the development of more precise methods for the measurement of small changes in the quantity of intracellular water in human subjects.

\section{SUMMARY}

1. Restriction of dietary sodium to 7 meq./day caused statistically significant reductions in the average blood pressures of five patients with uncomplicated hypertension. These reductions were due to the limitation of dietary sodium, since no blood pressure changes had been observed during a preliminary equilibration stage of two to four months duration in which the low sodium diet was supplemented with salt tablets (10 grams/day). Weight losses and large variations in the intakes of protein and of water during this time were without significant effects on the blood pressure.

2. Following withdrawal of the salt supplement, the patients lost 14 to 20 per cent of their exchangeable sodium during the first month of adap- tation and then apparently attained balance. On readministration of salt 10 weeks later, the patients reaccumulated sodium approximately to the control level.

3. On the supposition that the lost sodium was derived from extracellular fluid, the losses of body water appeared to be disproportionately small. The interpretation offered was that the surplus extracellular water, not excreted with its sodium, shifted into an intracellular position and thereby increased cellular hydration by about 5 per cent. The reverse effects were observed following readministration of salt. The hypothesis was advanced that the low sodium diet exerted its beneficial effect in the hypertensive patients by causing an increase in cellular hydration.

\section{REFERENCES}

1. Eichelberger, L., The distribution of water and electrolytes between blood and skeletal muscle in experimental hypertension. J. Exper. Med., 1943, 77, 205.

2. Laramore, D. C., and Grollman, A., Water and electrolyte content of tissues in normal and hypertensive rats. Am. J. Physiol., 1950, 161, 278.

3. Dole, V. P., Dahl, L. K., Cotzias, G. C., Eder, H. A., and Krebs, M. E., Dietary treatment of hypertension. Clinical and metabolic studies of patients on the rice-fruit diet. J. Clin. Invest., 1950, 29, 1189.

4. Marinelli, L. D., Quimby, E. H., and Hine, G. J., Dosage determination with radioactive isotopes. II. Practical considerations in therapy and protection. Am. J. Roentgenol., 1948, 59, 260.

5. Fisher, R. A., Statistical Methods for Research Workers. Oliver \& Boyd, Ltd., London, 1944, 9th Ed., p. 114.

6. Jarvett, A. A., Statistical methods used in the measurement of radioactivity. U. S. Atomic Energy Commission, AECU-262, Mon P-126, June 17, 1946.

7. Duncan, G. G., Diseases of Metabolism : Detailed Methods of Diagnosis and Treatment. W. B. Saunders Co., Philadelphia, 1942, p. 938. 